\title{
More views on Imanishi-Kari
}

Professor Mark Ptashne describes evidence to explain the disputed Cel/paper, Dr Herman N Eisen (who conducted the MIT inquiry in 1986) concurs, Dr John Cairns (in letter to an unidentified official of the US National Academy) says the affair is the equivalent of Watergate and a former co-worker offers a testimonal to Imanishi-Kari.

\section{From Mark Ptashne (Harvard)}

IN his account in Nature ${ }^{1}$ of the MIT inquiry into the "Baltimore affair", Dr Herman Eisen raises one scientific point, and that point deserves some comment.

The central claim of Weaver et $a l_{.}{ }^{2}$ is as follows: introduction into a mouse of a rearranged gene encoding an immunoglobulin heavy chain with a specific idiotype elicits production of antibody heavy chains that bear the transgene idiotype; remarkably, many of these chains are encoded entirely by endogenous genes. Why might one find such a result important? In the authors' words, the result “....suggests that a rearranged gene introduced into the germ line can activate powerful cellular regulatory influences." According to one interpretation, the result could be a manifestation of the workings of an "idiotype network"; the idiotype network idea, suggested several years ago, has not received strong experimental support.

Two papers published in $1989^{3,4}$ address the question of whether the central claim might be generally correct. Both of these papers report the use of a mouse to which has been added a rearranged heavy-chain immunoglobulin gene - the idiotype encoded by this gene is different from the one studied by Weaver $e t a L^{2}$ As in Weaver et al., however, the transgene in these new experiments encodes a heavy chain of type $\mathrm{mu}^{\mathrm{a}}$, whereas the endogenous mu gene is of type $\mathrm{mu}^{\mathrm{b}}$. The paper of Rath et al. ${ }^{4}$ shows that these transgenic mice do express antibodies with idiotype of the transgene (called AD8-reactive), but "...all detectable AD8 reactivity was associated with molecules expressing the $\mathrm{mu}^{\mathrm{a}}$ allotype and none was detected in association with molecules lacking mu$^{a}$." (Note, for example, that the idiotype was found neither on endogenous $\gamma$ nor on endogenous $\mu$ chains.) Moreover, these idiotype-bearing $\mathrm{mu}^{\mathrm{a}}$ chains were found in association with $\mathrm{mu}^{\mathrm{b}}$ heavy chains in chimaeric molecules, an additional finding relevant to the controversy over Weaver et $a l^{2}$ as I explain below.

The paper of Durdick et al. ${ }^{3}$ finds that following immunization of these transgenic mice with the antigen that interacts with the

1. Eisen, H. Nature 351, 343 (1991).

2. Weaver, D., Reis, M. H., Albarese, C., Costantini, F., Baltimore, D. \& Imanishi Kari, F. Cell 45, 247-259 (1986).

3. Durdick, J. et al. Proc. natn. Acad. Sci. U.S.A. 86, 23462350 (1989).

4. Rath, S., Durdick J., Gerstein, R. M., Selsing, E. \& Nisonoff, A. J. Immun. 113, 2074-2080 (1989).

5. O'Toole, M. Nature 351, 180-183 (1991). transgene product, idiotype can be found associated with $\gamma$ heavy chains. Molecular analysis reveals, however, that the heavy chains of these antibodies are encoded by recombinants formed between the variable region of the transgene and an endogenous $\gamma$ gene. These two papers thus fail to replicate, in an experiment involving a different idiotype, the central claim of Weaver et al. ${ }^{2}$.

Dr Eisen, in his statement I alluded to at the beginning of this letter, says of $\mathrm{Dr} M$. O'Toole, "But I did not agree with several of her arguments. For example, her assertion that some of the results could be explained by heterodimer formation, which I take to mean $\mu-\gamma$ chimaeric molecules is highly implausible". But O'Toole was referring not to $\mu-\gamma$ chimaeras but to $\mu-\mu$ chimaeras: her memo to Eisen dated 6 June 1986, states "In sum-

To an officer of the National Academy of Sciences, 28 June 1991

AFTER our conversation, I thought I should produce a list of what I believe are the most important components of the so-called Baltimore affair.

(1) It seems that O'Toole was right in saying that the paper should be withdrawn (as eventually it was), right in thinking that there may have been misconduct (as the Secret Service now claim to have demonstrated) and right in her alternative interpretation for the central section of the paper (see the letter from Mark Ptashne).

(2) Nothing now is likely to stop the affair from progressing to its final disastrous conclusion, and I do not see how the authors of the paper can escape public censure, at the very least. About the only question remaining is whether anyone will actually go to jail.

(3) The whole affair seems to be turning into a kind of scientific Watergate and, like Watergate, is surely destined to be dissected and analysed for years to come.

(4) Some of the blame falls on the scientific community - on those who arranged and conducted the initial, perfunctory inquiries - on the National Academy for not demanding a proper investigation - and on the many scientists who did not look at the evidence and, instead, construed the whole business as a Congressional manoeuvre to attack the scientific establishment. (I remember that originally I too felt that the row was probably a political stunt.)

(5) Because the establishment has played such an undistinguished role, we may find it increasingly difficult to maintain the idea mary, the data on transgenic sera in figures 1 and 2 can be explained...by heterodimer formation." In fact, Fig. 1 of Weaver et al. ${ }^{2}$ involves testing only for mu chains, and Fig. 2 does not involve any isotyping. O'Toole's explanation, according to Rath et al. ${ }^{4}$, is eminently reasonable and readily testable.

I thank Herman Eisen for graciously reviewing this matter with me (see below). $\square$

\section{From Herman N. Elsen (MIT)}

$\mathrm{S}_{\mathrm{R}}$ - In my response ${ }^{1}$ to Dr O'Toole's previous comments ${ }^{5}$ I referred to her earlier suggestion (in a June 6, 1986 memo) that "heterodimer" formation could account for some of the reactivity in sera from the transCell . I took the term heterodimer to mean a mixed $\mu-\gamma($ or $\mu-\alpha)$ dimer involving one $\mu$

that science is a genuine search for truth and that scientists are generally honourable and deserving members of society. Simply at the mundane level of money, I could imagine fund-raising for the Academy becoming much harder if Congress is left with the image of the Academy as the organization that sided with Baltimore right or wrong, through thick and thin, to the bitter end.

(6) So I believe that, although it now too late to do much good, the Academy should be issuing a statement (a) reaffirming the aims of science and (b) pointing out that if the rules and principles of science had been observed we wouldn't now be in this mess. For most scientists, science is the pursuit of a truth that is external to our wishes. This truth is quite unlike the verdict of a court of law because it does not depend on advocacy. Instead, each of us has to be responsible for the accuracy of our own statements; we cannot simply count on others to correct our mistakes. Each of us knows more about our own experiemnts than anyone else, and when something goes wrong we have to speak up. If the Academy does not say something like that, American scientists may end up with the same kind of public image as many of the country's lawyers and politicians - which would do a great disservice to all young scientists.

Department of Cancer Biology, Harvard School of Public Health, 665 Huntingdon Avenue,

Boston, Massachusetts 02115, USA genic mice studied in the disputed paper in 
chain encoded by the transgene and one $\gamma$ (or $\alpha)$ chain encoded by an endogenous gene. Such a heterodimer seemed unlikely to be stable because of extensive amino-acid sequence differences between $\mu$ and other types of immunoglobulin heavy chains. Recently, however, it has been called to my attention (see Prashne's accompanying letter) that what O'Toole meant by heterodimer was not $\mu-\gamma$ (or $\mu-\alpha)$ but a mixed IgM molecule (a polymer with 10 chains per molecule) in which some of the $\mu$ chains were encoded by the transgene and others by endogenous $\mu$ genes. In contrast to heterodimers, such mixed $\mu-\mu$ heteropolymers are certainly plausible and $O$ 'Toole's suggestion would thus appear to have been reasonable.

Nonetheless, there was no guarantee at the time that the critical antigenic determinants of the transgene's heavy chain ("idiotype") would be manifest in mixed IgM molecules, where various $\mu$ chains can interact. Hence, even if there had been no misunderstanding about the matter in the 1986 inquiry, I would nevertheless have felt that further research was needed to evaluate her proposed explanation. Some of the further research has indeed been reported in a paper from Alfred Nisonoff's laboratory (Rath et $a l^{4}{ }^{4}$ ). The paper contains some elegant analytical immunochemistry showing that in another transgenic mouse strain, involving a different $\mu$ chain transgene, mixed IgM molecules (transgene $\mu$ chains plus endogenous gene $\mu$ in various proportions) do exist; it also shows that in these molecules the transgene's idiotype is manifest and is due exclusively to the transgene's $\mu$ chain. The results in Rath et al. may well portend what would be found if sera from the transgenic mice used in the disputed Cell paper (M54 and M95 strains) were similarly analysed.

There are, however, several reasons for exercising caution in extrapolating now from the study by Rath et al. to the Cell paper. (1) The Cell paper claimed that some hybridomas did not produce IgM (but presumably produced IgG or IgA) and were still idiotype positive. The existence of such hybridomas is still under dispute; for such hybridomas mixed $\mu-\mu$ molecules would not be relevant. (2) In Rath et al. the transgene's idiotype was detected by a monoclonal antibody, whereas in the Cellpaper it was detected by a polyclonal antibody population; the range of reactivities (or cross-reactivities) exhibited by polyclonal antibodies are expected to be substantially broader than those of any particular monocolonal antibody. (3) It is not yet known what endogenous immunoglobulin genes are expressed in the transgenic mouse strain studied by Rath et al. In the strains studied in the Cell paper these genes appear to be confined to an unusual, limited set at the extreme 3 ' end of the huge array of $\mathrm{VH}_{\mathrm{H}}$ gene segments (represented by the V81X family). The point here is that immunoglobulins whose variable (heavy chain) domains are encoded by V81X-like genes have been claimed by several laboratories to be highly cross-reactive with diverse reagents (including many anti-idiotypes). Although the validity of this claim is still not settled, it is important to keep in mind that diverse transgenic mouse strains might express different sets of endogenous immunoglobulin genes and thus differ in their reactivities.

In the excellent paper by Durdik et al. ${ }^{3}$ hyperimmunized transgenic mice were found to express many recombinant genes (linking the variable sequence of the transgene to the constant sequence of an endogenous $(\gamma)$ gene. Their immunization programme also resulted in strong selection of those B cells that expressed both the transgene and a particular light chain gene (required for detection of a particular form of the idiotype). The relevance of this paper to the Cell paper (which also described a hybridoma with a similar recombinant gene) is limited, because in the Cell, paper only nonimmunized mice were analysed.

Besides being elegant studies in their own right, Rath et-al. and Durdik et al. are welcome demonstrations that the scientific process itself is the most effective way of resolving scientific disputes. I am grateful to Professor Mark Ptashne for calling these papers to my attention and for suggesting that my comments accompany his. I look forward to additional research that bears on disputed scientific issues in the Cell paper.

\section{From Nicholas Yannoutsos (NIMR, MIII HIII)}

I SHOULD like to comment on the investigation of the paper published in Cell in 1986 whose principal author was $\mathrm{Dr}$ Thereza Imanishi-Kari. I worked with Imanishi-Kari from about October 1985 to May 1988 and I feel it is my duty to put on record my personal experience of that period.

My work was mainly the establishment of transfectant cell lines and transgenic mouse lines carrying the membraneless form of the 17.2.25 immunoglobulin heavy-chain gene, their molecular, serological and FACS analysis, and comparison to cell lines that carried the intact gene versus non-transfected cell lines and normal mice. This was always compared with a parallel analysis of the transgenic mouse line which carried the intact gene and whose serological, pre-B and hybridoma study had been reported in the 1986 Cell paper.

My work, like most of the work in Imanishi-Kari's laboratory, was based on the findings reported in that paper and I want to make clear that, in my personal experience, what was reported in that paper was not an isolated collection of ambiguous experiments. Instead, it was part of continuing research conducted with genuine and critical interest. I must stress the "critical interest" because Imanishi-Kari herself and other people in her laboratory, including myself, have painstakingly repeated time and again the work reported in the Cellpaper. This was done with improved and diverse techniques and approaches and alongside further experiments that might clarify the mechanisms involved. All this was done in an atmosphere of openness and intellectual integrity that kept everybody alert to the possibility of trivial or artefactual explanations for what was obviously a profound effect on the immunology of the transgenic mouse under study. Not only did all the people in the laboratory participate actively, but so did people from collaborating or just neighbouring laboratories. The data were scrutinized, discussed and analysed extensively, in group and departmental meetings or even as they were coming out "raw" in the corridor and at the benches of MIT and Tufts.

I cannot emphasize enough the genuine attitude with which Imanishi-Kari conducted her own work and invited other people's participation, criticism and contribution, and her willingness to pursue not a particular theory, but any valid interpretation for her own findings and the findings of other researchers in related work. She was always in the laboratory, working long and hard hours and in constant communication with the people in it. She was particularly strict about the technical aspects of the work and demanded that every experiment be well controlled and repeatable. Her strictness might occasionally frustrate the false pride of an individual worker, but it was also a lesson in the essential modesty, dedication and correctness with which scientific work must be conducted and of which Dr Imanishi-Kari was herself the best example.

Several aspects of the originally reported work are repeated and further analysed in a recent publication (Iacomini et al., Int. Immun. 3, 185-196; 1990). Among the experiments reported in this publication is the Abelson transformant pre-B analysis of the transgenic mouse carrying the membraneless form of the 27.2.25 Ig heavy chain gene. As I mentioned above, I have worked with this mouse and compared it to the original transgenic mouse. In the process of such comparison (unpublished), I have done RIAs in which sera from both transgenic mice were screened with anti- $\lambda$, anti- $\kappa$, anti$\mu \mathrm{a}$ (BET-1 and anti- $\mu$ b antibodies on plates coated with monoclonal or polyclonal anti17.2.25 anti-idiotype antibody. So the disputed serology on the original transgenic mouse was repeated and shown to be essentially as reported in the 1986 Cell paper.

Since the beginning of this affair, the investigating committees and the scientific journals that have been reporting it appear to have focused only on the state of the notebooks that contain the initial experiments on this transgenic mouse. No due consideration seems to have been given to whether the reported findings are actually valid and independently reproducible. Despite the extensive coverage of this case, it is quite unclear to me, and no doubt to most people familiar with the work, what were the real scientific grounds for the retraction of the $1986 \mathrm{Cell}$ paper by several (but not all) of its authors, or in fact for this whole "Baltimore affair". $\square$ 